\title{
Exploring the benefits of participation in community-based running and walking events: a cross-sectional survey of parkrun participants
}

Helen Quirk ${ }^{1 *}$ (D) Alice Bullas², Steve Haake², Elizabeth Goyder ${ }^{1}$, Mike Graney ${ }^{3}$, Chrissie Wellington ${ }^{3}$, Robert Copeland ${ }^{2}$, Lindsey Reece ${ }^{4}$ and Clare Stevinson ${ }^{5}$

\begin{abstract}
Background: Whilst the benefits of physical activity for health and wellbeing are recognised, population levels of activity remain low. Significant inequalities exist, with socioeconomically disadvantaged populations being less physically active and less likely to participate in community events. We investigated the perceived benefits from participation in a weekly running/walking event called parkrun by those living in the most socioeconomically deprived areas and doing the least physical activity.

Methods: A cross-sectional online survey was emailed to 2,318,135 parkrun participants in the UK. Demographic and self-reported data was collected on life satisfaction, happiness, health status, physical activity, motives, and the perceived benefits of parkrun. Motivation, health status and benefits were compared for sub-groups defined by physical activity level at parkrun registration and residential Index of Multiple Deprivation.

Results: 60,000 completed surveys were received (2.7\% of those contacted). Respondents were more recently registered with parkrun ( 3.1 v. 3.5 years) than the parkrun population and had a higher frequency of parkrun participation (14.5 v. 3.7 parkruns per year). Those inactive at registration and from deprived areas reported lower happiness, lower life satisfaction and poorer health compared to the full sample. They were more likely to want to improve their physical health, rather than get fit or for competition. Of those reporting less than one bout of activity per week at registration, $88 \%$ (87\% in the most deprived areas) increased their physical activity level and $52 \%$ (65\% in the most deprived areas) reported improvements to overall health behaviours. When compared to the full sample, a greater proportion of previously inactive respondents from the most deprived areas reported improvements to fitness ( $92 \%$ v. $89 \%)$, physical health (90\% v. $85 \%)$, happiness $(84 \%$ v. $79 \%)$ and mental health $(76 \%$ v. $69 \%)$.
\end{abstract}

\footnotetext{
* Correspondence: h.quirk@sheffield.ac.uk

${ }^{1}$ School of Health and Related Research, The University of Sheffield, 30 Regent St, Sheffield S1 4DA, UK

Full list of author information is available at the end of the article
}

(C) The Author(s). 2021 Open Access This article is licensed under a Creative Commons Attribution 4.0 International License, which permits use, sharing, adaptation, distribution and reproduction in any medium or format, as long as you give appropriate credit to the original author(s) and the source, provide a link to the Creative Commons licence, and indicate if changes were made. The images or other third party material in this article are included in the article's Creative Commons. licence, unless indicated otherwise in a credit line to the material. If material is not included in the article's Creative Commons licence and your intended use is not permitted by statutory regulation or exceeds the permitted use, you will need to obtain permission directly from the copyright holder. To view a copy of this licence, visit http://creativecommons.org/licenses/by/4.0/ The Creative Commons Public Domain Dedication waiver (http://creativecommons.org/publicdomain/zero/1.0/) applies to the data made available in this article, unless otherwise stated in a credit line to the data. 
Conclusion: The least active respondents from the most socioeconomically deprived areas reported increases to their activity levels and benefits to health and wellbeing since participating in parkrun. Whilst the challenge of identifying how community initiatives like parkrun can better engage with underrepresented populations remains, if this can be achieved they could have a critical public health role in addressing inequalities in benefits associated with recreational physical activity.

Keywords: Cross-sectional study, Inequalities, Deprivation, Physical activity, Community event

\section{Background}

In its Global Action Plan on Physical Activity 20182030, the World Health Organization (WHO) identified a need for physical activity opportunities that use public spaces and engage whole communities [1]. Mass participation physical activity events have been recognised for their public health potential given their population reach, growing popularity and community context [2] and potential to engage patient populations [3]. However a criticism of mass sporting or physical activity events is that they can attract those who are already active and from more affluent areas $[4,5]$. 'One-off' mass participation physical activity or sporting events may also have limited potential to leverage sustained behaviour change [2].

Starting in London, United Kingdom (UK) in 2004, parkrun is a charity that organises free, weekly (and thus regular), timed $5 \mathrm{~km}$ mass participation events for people to participate as runners/walkers (running or walking the $5 \mathrm{~km}$ course) or volunteers (permanent volunteers are responsible for the delivery of the event every week and episodic volunteers carry out event day volunteering duties such as marshalling, timekeeping, scanning barcodes, handing out finish tokens or tail walking). There is now a growing number of weekly parkrun events worldwide across 23 countries attracting millions of international participants and a global network of over 375,000 volunteers [6]. parkrun (www.parkrun.com) has been recognised in WHO's Global Action Plan as a working example of "regular mass-participation initiatives in public spaces, engaging whole communities, to provide free access to enjoyable and affordable, socially and culturally appropriate experiences of physical activity (page 66)" [1].

parkrun events are organised by local volunteer teams and the opportunity to participate is open to all. Events are promoted as being inclusive to people from all backgrounds and abilities and research evidence would support its perceived inclusivity and ability to create a supportive environment [7-11]. Participation in parkrun is free: people register online and receive a unique 'barcode' containing their parkrun ID number that they take to any event across the world that is scanned and used to $\log$ attendance and completion time. An increasing proportion of events have been established in more socioeconomically disadvantaged areas in the UK, with higher population density resulting in better geographical access to events for those living in these areas [12, 13]. Inequalities in registration and participation persist despite parkruns being located closer to more socioeconomically disadvantaged areas [12,14] with $13.1 \%$ of those participating at least once live in the most socioeconomically deprived areas of the UK (see Table 1).

Previous research has demonstrated that individuals who live in socioeconomically deprived areas and are physically active may experience much better health and quality of life than their neighbours who are less active [15]. In a cohort study of 354 new parkrun participants in the UK, Stevinson and Hickson [16] also showed that parkrun participation is associated with significant positive changes in health and wellbeing over 6 and 12 months, including level of physical activity. However previous parkrun studies have not been designed to explore the relationship between socioeconomic deprivation and changes in physical activity for those inactive before participating and the perceived benefits of participation [16-18].

In 2018, a Health and Wellbeing Survey of UK parkrun participants was undertaken [19]. In this manuscript, we have used a large and diverse sample from that survey of parkrun runners/walkers and runners/walkers who volunteer to explore the following:

Table 1 Population characteristics of parkrun participants

\begin{tabular}{lcc}
\hline Parkrun participants (census date 3rd December 2018) & \\
\hline $\mathrm{n}$ & $1,549,806$ & \\
Proportion female & 759,050 & $51.3 \%$ \\
Mean age of participants (years) & 40.5 & \\
Index of multiple deprivation & & \\
$\mathrm{n}$ & $1,385,961$ & \\
$\quad$ Quartile 1 & 181,561 & $\mathbf{1 3 . 1 \%}$ \\
Physical activity level at registration & & \\
$\quad \mathrm{n}$ & $1,656,006$ & \\
$\quad$ Less than one day per week of activity & 109,296 & $6.6 \%$ \\
Mean years registered with parkrun & 3.5 & \\
Mean number of parkruns run/walked per year & 3.7 & \\
\hline
\end{tabular}


1) the motivation for first participating in parkrun as a runner or walker;

2) the self-reported health and wellbeing benefits from participation in parkrun.

We focus on sub-samples representing those who were previously inactive at registration, those from the most socioeconomically deprived areas, or both.

\section{Methods}

\section{Procedure}

Ethical approval for the study was granted by Sheffield Hallam University Research Ethics Committee on 24/07/ 2018 (reference number: ER7034346) and approval was granted from the parkrun Research Board. The study used an online survey, incorporating wherever possible existing measures used in health and wellbeing research. An advisory team, created using the parkrun Research Board and academics, were consulted to longlist and then shortlist the questions used in the survey. Each questionnaire or question was selected using the following criteria: relevance; validity; reliability; length; previous use. If suitable previous questionnaires or questions could not be identified, the research team developed study-specific questions to capture the outcome (as highlighted in the Methods section). The survey length and literacy were tested and re-tested via members of the research team and the advisory team. The reporting adheres to established standards for reporting internetbased surveys; The Checklist for Reporting Results of Internet E-Surveys (CHERRIES) [20].

\section{Population and participants}

The sample was drawn from all parkrun registrants in the UK. Registrants received an email from parkrun containing a link to the survey. Survey participants had to be aged 16 or over and the survey was only available in online format and in the English language; there were no other explicit exclusion criteria. In this manuscript, we use the data from respondents who identified in the survey as runners/walkers and runners/walkers who also volunteer at parkrun. Runners/walkers are those who participate in parkrun by running or walking the $5 \mathrm{~km}$ course. Runners/walkers who also volunteer are those who participate in parkrun as a volunteer as well as a runner/walker. Findings relating to the health and wellbeing of parkrun volunteers and the perceived impact of volunteering at parkrun will be published separately.

\section{The survey}

The measures in the survey are described fully in Additional file 1 with a full copy of the survey, including wording for consent. The list below describes the subset of measures used in this study.

\section{Demographics}

Demographic data included date of birth, gender, ethnicity, employment, home parkrun (the parkrun event they were most closely affiliated with), socioeconomic status and long-term health conditions.

Socioeconomic status was assessed using index of multiple deprivation (IMD) for Lower Level Super Output Areas (LSOA) derived from the postcode provided by the individual at parkrun registration. LSOAs are the smallest units from which Population Census data is compiled and onto which official data on socioeconomic context is mapped by the Office of National Statistics [21]. IMD scores were classified into four quartiles Q1 to Q4 where Q1 represented the most deprived areas.

Long-term health conditions were recorded by selfreport using the question: "Are your day-to-day activities limited because of a health condition or disability which has lasted, or is expected to last, at least 12 months? Include conditions related to old age, sensory deficits, mobility problems, developmental conditions, learning impairments and mental health" followed by a list of health conditions if they answered 'yes, limited a lot' or 'yes, limited a little' (56 health conditions were listed in total, plus an 'other, please specify' option). See Additional file 1 for the survey question.

One question asked participants to state whether they most closely identified as a parkrun runner/walker, a parkrun runner/walker and volunteer or a parkrun volunteer. Respondents were asked to provide their parkrun ID number to enable their survey responses to be matched to the parkrun database that holds their parkrun registration details (e.g. postcode, activity level at registration) and participation information (e.g. number of parkruns completed). See 'parkrun data' section below for more details.

\section{Life satisfaction and happiness}

Two of the four personal wellbeing questions asked in the UK's Office of National Statistics (ONS) Annual Population Survey [22] were used as measures of life satisfaction and happiness: 1) "Overall, how satisfied are you with your life nowadays?" and 2) "Overall, how happy did you feel yesterday?" Statements were rated on a 10-point visual analogue scale where 0 is "not at all", and 10 is "completely". Life satisfaction and happiness were chosen from the four ONS measures because these aspects of wellbeing were not already captured in other measures used in the survey (see Additional file 1 for a full list of the questions used in the survey). Despite these ONS wellbeing measures being used extensively in large UK population surveys, there are no reported psychometric properties (e.g., validity). Each answer is taken at face value and cut-offs determine high and low scores. 


\section{Subjective health status}

Subjective health status was measured using the EuroQoL visual analogue scale (EQ-VAS) [23] which asks: "We would like to know how good or bad your health is TODAY. This scale is numbered from 0 to 100. 100 means the best health you can imagine. 0 means the worst health you can imagine. Please enter a number in the box below to indicate how your health is TODAY." The VAS was presented vertically with the label "the best/worst imaginable health" on the top/bottom and numbers ranging from 0 to 100 along the side. Permission was granted by EuroQol Research Foundation for its use. The construct validity of EQ-VAS has been reported as satisfactory [24].

\section{Motivation for participating in parkrun as a runner/walker}

Motivation for participation in parkrun was measured with a question developed by the research team for the purpose of this study: "What motivated you to first participate at parkrun as a runner or walker?" Respondents were asked to select a maximum of three answers out of a possible 21 motives. Examples of motives included; "to improve my physical health", "to improve my mental health", "to manage my weight", "to improve my happiness", "to meet new people" and "to spend time with friends" (see Additional file 1 for full list of motives). The 21 choices were displayed in randomised order to help reduce response bias. The final choice was "other" and, if selected, respondents were asked to specify the motive. Given that this was a study-specific question, there are no psychometric properties to report for this measure.

\section{Self-reported physical activity}

Self-reported physical activity was measured using three different measures: 1) a single item four-week recall physical activity question that is also asked at parkrun registration; 2) a single item 1 week recall physical activity question [25]; and 3) the International Physical Activity Questionnaire Short Form (IPAQ-SF) [26].

The four-week recall question asked: "Over the last 4 weeks, how often have you done at least 30 minutes of moderate exercise (enough to raise your breathing rate)?" Respondents could answer: less than once per week, about once per week, about twice per week, about three times per week, four or more times per week, rather not say, don't know. This question was chosen as it was also asked at parkrun registration, allowing direct comparison between pre-parkrun participation and post-parkrun participation. Given that this was a parkrun-specific question, there are no psychometric properties to report for this measure.

This single-item physical activity measure was developed by Milton, Bull [25] and asks: "In the past week, on how many days have you done a total of 30 minutes or more of physical activity, which was enough to raise your breathing rate. This may include sport, exercise, and brisk walking or cycling for recreation or to get to and from places, but should not include housework or physical activity that may be part of your job." Respondents could answer: 0 days, 1 days, 2 days, 3 days, 4 days, 5 days, 6 days, 7 days. This has been validated against the Global Physical Activity Questionnaire in a UK sample of 240 adults [25].

Physical activity was also measured using the International Physical Activity Questionnaire short form (IPAQ-SF) [26]. The IPAQ-SF is a validated, subjective measure of physical activity [27] and was asked as an optional question at the end of the survey, to enable comparison across the different physical activity measures and to give additional insight into the intensity of activity being done. Respondents answered 7 questions on the frequency, intensity (moderate, vigorous, walking, sitting) and duration of physical activity participation over the past 7 days.

\section{Perceived impact of running/walking at parkrun}

The perceived impact of parkrun was measured using a question developed by the research team for the purpose of this study: "Thinking about the impact of parkrun on your health and wellbeing, to what extent has running or walking at parkrun changed:" Respondents were presented with a list of 15 potential impacts and asked to rate each one on the following 5-point scale: much worse, worse, no impact, better, much better. Examples of impacts included: "your physical health", "your mental health", "your ability to manage your weight", "your happiness", "the number of new people you meet" and "the amount of time you spend with family" (see Additional file 1 for full list of perceived impacts). The answer choices were displayed in randomised order to help reduce response bias. The final choice was "other" and, if selected, respondents were asked to specify the impact. Given that this was a study-specific question, there are no psychometric properties to report for this measure.

\section{Parkrun data}

Additional data was exported from the parkrun database when enough personal details were provided to enable data matching. Additional data matched to responses included the following: postcode provided at parkrun registration; date of parkrun registration; self-reported physical activity level at registration using the four-week recall question; and total number of parkruns completed since registration. 


\section{Data collection}

Pilot testing was carried out on a randomly selected sample of 200 UK participants (aged 16 or over). Subsequent power calculations suggested that the survey would have to be sent to the full parkrun population to allow segmentation to a sub-sample from socioeconomically deprived areas (derived by postcode) and who were previously inactive at registration (less than one bout of activity a week). The survey was distributed between 29th October and 3rd December 2018.

The survey used Qualtrics online survey software [28]. The web link contained an introductory page with a participation information sheet and a confirmation box to indicate it had been read, understood and consent given to be part of the take part. Only people emailed the web link could access the survey. View rate of the survey was not captured. The survey was open for 5 weeks from 29th October 2018 with staggered sending of emails due to email server limitations. Reminders were emailed after 1 week. There were no incentives offered for taking part in the survey.

Questions were asked in the order presented in Additional file 1, with the exception of the International Physical Activity Questionnaire Short Form (IPAQ-SF), which was asked as a final, optional question due to its length and to keep it apart from the other physical activity measures used earlier in the survey. Questions were not randomised, but response choices within some questions were (see Additional file 1).

Adaptive questioning was utilised, such that certain questions were displayed based on answers to previous questions. For example, people who reported being walkers/runners did not see questions about volunteering at parkrun. There was a maximum of 47 questions, with an average of 4.3 questions per page and a maximum number of 11 screens (pages) of questions (total question number and page number were shorter depending on how respondents answered questions).

Questions were optional (i.e. non-compulsory) with the exception of the question about parkrun participation type (to enable the appropriate questions to be presented to the respondent), one question about long-term health conditions and two questions about life satisfaction and happiness. Respondents could go back and forth within the survey to review or change answers. Upon clicking 'submit', answers could not be changed. With consent, partially completed survey responses were saved and data kept for analysis unless the respondent requested removal by contacting the research team.

\section{Data handling}

Survey returns that included identifiers (parkrun ID number, name, date of birth, home parkrun) were matched, with consent, to parkrun registration data for
$74 \%$ of survey respondents (the remaining $26 \%$ did not contain enough information to allow the match). All data was pseudonymised after matching with parkrun registration data. Data was handled in accordance with the Data Protection Act 2018 and the General Data Protection Regulation 2018. Data cleaning and analysis was carried out in Microsoft Excel, SPSS (IBM SPSS Statistics 24.0) and MATLAB (version 13.0b, MathWorks, USA).

Duplicate responses were identified by their unique Qualtrics code assigned during the survey and only the latest time-stamped response retained. Responses were excluded if they consented and filled out some or all demographic data but did not fill out any other survey questions to enable analysis. Six respondents were removed either due to abusive comments in free text, because of nonsensical responses, or both. Respondents were not obliged to answer all questions and partially completed surveys were included in the analysis, meaning the sample size varied across each analysis. Cases with missing data on certain variables were omitted from that specific analysis (listwise deletion) and we have reported the relevant sample sizes in all tables.

\section{Data analysis}

Descriptive statistics were used to characterise the respondents and compare them to the total population of parkrun registrants from which they were drawn. Subsample analyses where then undertaken to compare health and wellbeing, motivation for participation and self-reported benefits of participation between groups defined by socioeconomic deprivation status as well as their self-reported activity level at registration. Respondents from the most socioeconomically deprived areas (IMD quartile 1) are labelled 'deprived sub-sample' and those who self-reported as being the least active at parkrun registration (i.e. less than one bout a week) are labelled 'inactive sub-sample'. Respondents from the most socioeconomically deprived areas and the least active at registration are labelled 'deprived/inactive sub-sample'.

For descriptive statistics, we report percent, mean, median and interquartile range (IQR). Data such as age, happiness, life satisfaction, health today, parkruns per year, years registered with parkrun and the single physical activity question were non-parametric. Group comparisons were carried out using the MannWhitney $\mathrm{U}$ test. The alpha level used as the criterion for statistical significance in all inferential tests was $p<0.05$ or lower. Effect sizes were calculated using Cohen's $d$ using a pooled standard deviation with sizes defined as follows: small 0.10; medium 0.5; large 0.8 ; very large 1.2; huge 2.0. 


\section{Results}

\section{Survey responses}

The survey resulted in 100,864 respondents (4.5\% participation rate). The following were removed from the analysis: 1) respondents who did not consent (1349); 2) respondents who consented to view the survey but did not answer any questions $(37,040) ; 3)$ respondents who had registered with parkrun but not participated (1787); 4) respondents who identified as parkrun volunteers (681), i.e. were not runners or walkers; and 5) respondents who provided invalid responses [7]. The dataset used in this manuscript had 38,071 who identified as runners/walkers and 21,929 who identified as runners/ walkers who volunteer, giving a combined data set of 60,000 (2.7\% completion rate).

\section{Demographic characteristics of respondents}

Table 1 shows the characteristics of parkrun population from its inception on 2nd October 2004 to 3rd December 2018. The mean age was 40.5 years with $51.3 \%$ female; 181,561 or $13.1 \%$ were from the most deprived areas while 109,296 or $6.6 \%$ were previously inactive at registration. They had run or walked approximately 3.7 parkruns per year and been registered with parkrun for around 3.5 years.

Table 2 shows that the deprived, inactive and deprived/inactive sub-samples had 4384, 2184 and 237 respondents respectively. The proportion of the full sample who were female was $51.7 \%$ (similar to the full parkrun population); this increased in the deprived, inactive and deprived/inactive sub-samples to 52.5, 54.8 and $56.1 \%$ respectively. The mean age of the full survey sample was older than the parkrun population (48.0 \pm 13.1 years compared to 40.5 years in the parkrun population). Mean age decreased for the deprived, inactive and deprived/inactive sub-samples to $44.3 \pm 12.7,45.6 \pm$ 12.6 and $43.6 \pm 12.0$ years respectively (all significant at $p<0.001$ with small to medium effect sizes).

The full sample was $96.4 \%$ White with $2.9 \%$ from a Black, Asian or other ethnic background; the latter increased for the sub-samples to $6.0 \%$ for the deprived/inactive sub-sample. $55.7 \%$ of the full sample were in full-time employment with an additional $14.0 \%$ part-time and $9.5 \%$ self-employed; $12.5 \%$ were retired, $3.1 \%$ were students and $1.2 \%$ were unemployed. The proportion in the sub-samples who were retired decreased (to a minimum of $4.4 \%$ for the deprived/inactive sub-sample) while those who were unemployed increased (to $3.1 \%$ for the deprived/inactive sub-sample).

Table 2 shows values for happiness, life satisfaction and health for the full sample and sub-samples. Those in the deprived sub-sample reported $2.3 \%$ lower happiness than the full sample $(7.35 \pm 1.80$ compared to
$7.52 \pm 1.72$ out of $10 ; p<0.001$; effect size $=0.10)$ and $2.3 \%$ less life satisfaction $(7.58 \pm 1.54$ compared to $7.76 \pm 1.46$ out of $10 ; p<0.001$; effect size $=0.12$ ). This reduction increased for the inactive sub-sample to $3.3 \%$ for happiness $(7.26 \pm 1.79 ; p<0.001$; effect size $=0.15)$ and $3.5 \%$ for life satisfaction $(7.48 \pm 1.53$; $p<0.001$; effect size $=0.19)$. The deprived/inactive sub-sample reported $5.3 \%$ less happiness $(7.11 \pm 1.95$; $p<0.01$; effect size $=0.24$ ) and $4.5 \%$ less life satisfaction than the full sample $(7.37 \pm 1.60 ; p<0.001$; effect size $=0.27)$. It should be noted that the sample size was small in the latter group $(n=237)$. In England and Wales, national happiness has been reported as 7.53 out of 10 and life satisfaction 7.69 out of 10 [22].

In terms of overall health as measured by the EQVAS, those in the deprived sub-sample reported $2.1 \%$ lower health scores than the full sample $(79.3 \pm 13.7$ compared to $81.0 \pm 12.7$ out of $100 ; p<0.001$; effect size $=0.13)$; those in the inactive sub-sample reported $4.6 \%$ lower health scores $(77.3 \pm 14.3 ; p<0.001$; effect size $=0.29)$ and the deprived/inactive sub-sample reported the greatest reduction at $7.8 \% \quad(74.7 \pm 15.2$; $p<0.001$; effect size $=0.50)$ compared to the full sample. It should be noted that there were only 225 respondents in the deprived/inactive sub-group.

\section{Motives for participating in parkrun}

Respondents to the survey were asked to select three motives for initially taking part in parkrun: the results are shown in Table 2. The first and second most reported motives for the full sample were 'to contribute to my fitness' (56.2\% of respondents) and 'to improve my physical health' (37.0\% of respondents). The proportions choosing fitness tended to decrease for the deprived and inactive sub-samples, while the proportions choosing physical health tended to increase. The rankings reversed for the deprived/inactive subsample, so that 'to improve my physical health' was the first-ranked motive (48.3\% of respondents) while 'to contribute to my fitness' was the second $(45.3 \%$ of respondents).

The motive 'to gain a sense of personal achievement' was ranked third in the full sample and had a similar proportion of respondents across the sub-samples (25.4 to $26.9 \%$ ). The fourth ranked motive in the full sample was 'to get a recorded time for a $5 \mathrm{k}$ ' at $21.4 \%$; this reduced to $11.7 \%$ for the inactive sub-sample and to $12.8 \%$ for the deprived/inactive sub-sample so that it was ranked seventh place. In contrast, the fifth ranked motive for the full sample was 'to manage my weight' (19.8\%); this moved up to third place for the inactive and deprived/inactive sub-samples (29.2 and 32.5\% respectively). 
Table 2 Data for participants who were runners/walkers and runners/walkers who volunteer. Data in grey-italic indicate numbers < 10. (Percentages may not sum to $100 \%$ due to rounding)

\begin{tabular}{|c|c|c|c|c|}
\hline \multirow[t]{2}{*}{ (a) Demographic } & \multicolumn{4}{|l|}{ Sample/sub-sample } \\
\hline & Full sample & $\begin{array}{l}\text { Deprived sub- } \\
\text { sample }\end{array}$ & $\begin{array}{l}\text { Inactive sub- } \\
\text { sample }\end{array}$ & $\begin{array}{l}\text { Deprived / inactive sub- } \\
\text { sample }\end{array}$ \\
\hline Survey responses (n) & 60,000 & 4384 & 2184 & 237 \\
\hline Proportion female & $51.7 \%$ & $52.5 \%$ & $54.8 \%$ & $56.1 \%$ \\
\hline \multicolumn{5}{|l|}{ Age (years) } \\
\hline$n$ & 59,618 & 4377 & 2183 & 237 \\
\hline Mean & 48.0 & $44.3^{z}$ & $45.6^{z}$ & $43.6^{z}$ \\
\hline Standard deviation & 13.1 & 12.7 & 12.6 & 12.0 \\
\hline Effect size & & 0.29 & 0.19 & 0.34 \\
\hline \multicolumn{5}{|l|}{ Index of multiple deprivation } \\
\hline $\mathrm{n}$ & 46,153 & 4384 & 2134 & 237 \\
\hline Quartile 1 & $9.5 \%$ & $100 \%$ & $11.1 \%$ & $100 \%$ \\
\hline Quartile 2 & $20.4 \%$ & & $22.2 \%$ & \\
\hline Quartile 3 & $30.0 \%$ & & $30.4 \%$ & \\
\hline Quartile 4 & $40.1 \%$ & & $36.3 \%$ & \\
\hline \multicolumn{5}{|l|}{ Physical activity level at registration } \\
\hline$n$ & 42,747 & 4041 & 2184 & 237 \\
\hline Inactive $<1$ per week & $5.1 \%$ & $5.9 \%$ & $100 \%$ & $100 \%$ \\
\hline Active $\approx 1$ per week & $11.5 \%$ & $11.3 \%$ & & \\
\hline Active $\approx 2$ per week & $22.8 \%$ & $22.5 \%$ & & \\
\hline Active $\approx 3$ per week & $33.8 \%$ & $34.0 \%$ & & \\
\hline Active $\geq 4$ per week & $26.9 \%$ & $26.3 \%$ & & \\
\hline \multicolumn{5}{|l|}{ Ethnicity } \\
\hline $\mathrm{n}$ & 59,340 & 4342 & 2167 & 233 \\
\hline White & $96.4 \%$ & $94.0 \%$ & $94.9 \%$ & $93.1 \%$ \\
\hline Black, Asian or Other ethnic background & $2.9 \%$ & $5.3 \%$ & $4.5 \%$ & $6.0 \%$ \\
\hline Rather not say & $0.8 \%$ & $0.8 \%$ & $0.6 \%$ & $0.9 \%$ \\
\hline \multicolumn{5}{|l|}{ Employment status } \\
\hline$n$ & 58,433 & 4277 & 2117 & 229 \\
\hline Full-time paid employment & $55.7 \%$ & $64.6 \%$ & $59.3 \%$ & $64.2 \%$ \\
\hline Part-time paid employment & $14.0 \%$ & $11.6 \%$ & $15.7 \%$ & $15.3 \%$ \\
\hline Fully retired & $12.5 \%$ & $7.4 \%$ & $8.1 \%$ & $4.4 \%$ \\
\hline Self-employed & $9.5 \%$ & $8.0 \%$ & $8.6 \%$ & $6.6 \%$ \\
\hline Student & $3.1 \%$ & $3.4 \%$ & $3.3 \%$ & $3.1 \%$ \\
\hline Unemployed and not working & $1.2 \%$ & $1.7 \%$ & $2.1 \%$ & $3.1 \%$ \\
\hline Other & $4.1 \%$ & $3.4 \%$ & $2.8 \%$ & $3.5 \%$ \\
\hline \multirow[t]{2}{*}{ (b) Health at survey } & Sample/sub-sample & & & \\
\hline & Full sample & $\begin{array}{l}\text { Deprived sub- } \\
\text { sample }\end{array}$ & $\begin{array}{l}\text { Inactive sub- } \\
\text { sample }\end{array}$ & $\begin{array}{l}\text { Deprived / inactive sub- } \\
\text { sample }\end{array}$ \\
\hline \multicolumn{5}{|l|}{ Happiness (0-10) } \\
\hline$n$ & 59,998 & 4384 & 2184 & 237 \\
\hline Mean & 7.52 & $7.35^{z}$ & $7.26^{z}$ & $7.11^{y}$ \\
\hline Standard deviation & 1.72 & 1.80 & 1.79 & 1.95 \\
\hline Effect size & & 0.10 & 0.15 & 0.24 \\
\hline
\end{tabular}


Table 2 Data for participants who were runners/walkers and runners/walkers who volunteer. Data in grey-italic indicate numbers < 10. (Percentages may not sum to $100 \%$ due to rounding) (Continued)

\begin{tabular}{lllll}
\hline Life satisfaction (0-10) & & & & \\
$\mathrm{n}$ & 59,993 & 4384 & 2183 & 237 \\
Mean & 7.76 & $7.58^{z}$ & $7.48^{z}$ & $7.37^{z}$ \\
Standard deviation & 1.46 & 1.54 & 1.53 & 1.60 \\
Effect size & & 0.12 & 0.19 & 0.27 \\
Health today (0-100) & 57,283 & & 225 \\
n & 81.0 & 4205 & $79.3^{z}$ & $74.7^{z}$ \\
Mean & 12.7 & 13.7 & 14.3 & 15.2 \\
& & 0.13 & 0.29 & 0.50
\end{tabular}

\section{(c) Motives}

Motives

n

(Rank) Proportion of $\mathrm{n}$ for top 10 motives

To contribute to my fitness

To improve my physical health

To gain a sense of personal achievement

To get a recorded time for a $5 \mathrm{k}$

To manage my weight

My friends, family or colleagues encouraged me to

To train for another sport/event

To improve my mental health

To feel part of a community

To spend time outdoors

(d) parkrun participation

Years registered with parkrun

$\begin{array}{ll}\mathrm{n} & 47,701 \\ \text { Mean } & 3.13 \\ \mathrm{SD} & 2.53 \\ \text { Median } & 2.61 \\ \text { Q1-Q3 } & 0.94-4.81\end{array}$

Effect size

Total parkruns run/walked

$\begin{array}{ll}\mathrm{n} & 45,708 \\ \text { Mean } & 46.0 \\ \text { Standard deviation } & 61.1 \\ \text { Median } & 21 \\ \text { Q1-Q3 } & 6-62\end{array}$

Effect size

Parkruns run/walked per year

\section{Sample/sub-sample}

Full sample

59,263
(1) $56.2 \%$
(2) $37.0 \%$
(3) $26.9 \%$
(4) $21.4 \%$
(5) $19.8 \%$
(6) $15.2 \%$
(7) $14.2 \%$
(8) $13.0 \%$
(9) $11.0 \%$
(10) $10.3 \%$

Sample/sub-sample

Full sample

Deprived
sample

(1) $52.2 \%$

(2) $39.5 \%$

(3) $26.0 \%$

(4) $22.0 \%$

(5) $21.4 \%$

(7) $15.1 \%$

(8) $13.9 \%$

(6) $16.8 \%$

(9) $11.3 \%$

(10) $10.2 \%$

4300

$2.71^{\mathrm{z}}$

2.30

2.17

$0.72-4.20$

0.17

4193
$39.2^{z}$
54.7
17
$5-51$

0.11
Inactive subsample

Deprived / inactive subsample

2161

234
(1) $50.6 \%$
(2) $45.3 \%$
(2) $49.1 \%$
(1) $48.3 \%$
(4) $25.4 \%$
(5) $25.6 \%$
(7) $11.7 \%$
(7) $12.8 \%$
(3) $29.2 \%$
(3) $32.5 \%$
(5) $24.5 \%$
(4) $26.1 \%$

(10) $6.7 \%$

(6) $17.1 \%$

(9) $6.8 \%$

(8) $8.2 \%$

(9) $8.1 \%$

(6) $18.8 \%$

(10) $6.0 \%$

(8) $10.3 \%$
Deprived / inactive subsample

Inactive subsample

237

$2.28^{z}$

1.80

1.84

0.68-3.46

0.34

232

$35.0^{x}$

48.2

15

$6-50 \quad 6-44$

$\begin{array}{ll}0.14 & 0.18\end{array}$ 
Table 2 Data for participants who were runners/walkers and runners/walkers who volunteer. Data in grey-italic indicate numbers < 10. (Percentages may not sum to $100 \%$ due to rounding) (Continued)

\begin{tabular}{lllll}
\hline $\mathrm{n}$ & 34,211 & 2942 & 1447 & 151 \\
Mean & 14.60 & $14.12^{\mathrm{x}}$ & $15.53^{\text {y }}$ & 14.78 \\
Standard deviation & 12.15 & 12.02 & 12.50 & 12.67 \\
Median & 11.3 & 10.7 & 12.2 & 11.0 \\
Q1-Q3 & $4.0-23.3$ & $3.9-22.5$ & $4.4-25.4$ & $3.9-24.1$ \\
Effect size & & 0.04 & 0.08 & 0.01
\end{tabular}

(e) physical activity at the survey

Sample/sub-sample

\begin{tabular}{|c|c|c|c|}
\hline $\begin{array}{l}\text { Full } \\
\text { sample }\end{array}$ & $\begin{array}{l}\text { Deprived sub } \\
\text { sample }\end{array}$ & $\begin{array}{l}\text { Inactive sub- } \\
\text { sample }\end{array}$ & rived / inactive sub-sample \\
\hline
\end{tabular}

Single activity question

$\begin{array}{lllll}\mathrm{n} & 59,967 & 4382 & 2183 & 236 \\ \text { Mean } & 3.59 & 3.45^{z} & 2.41^{z} & 2.47^{z} \\ \text { Standard deviation } & 1.77 & 1.81 & 1.67 & 1.71 \\ \text { Median } & 3 & 3 & 2 & 2 \\ \text { Q1 - Q3 } & 2-5 & 2-5 & 1-3 & 1-3 \\ \text { Effect size } & & 0.08 & 0.67 & 0.64 \\ \text { IPAQ n } & 45,496 & 3303 & 1568 & 171 \\ \begin{array}{l}\text { Proportion low or moderate physical } \\ \text { activity }\end{array} & 35.8 \% & 38.0 \% & 62.2 \% & 59.6 \% \\ \begin{array}{l}\text { Proportion high physical activity (health } \\ \text { enhancing) }\end{array} & 64.2 \% & 62.0 \% & 37.8 \% & 40.4 \%\end{array}$

Mann-Whitney test between full sample and sub-samples: ${ }^{\mathrm{x}} p<0.05 ;{ }^{\mathrm{y}} p<0.01 ;{ }^{\mathrm{z}} p<0.001$

Effect size was calculated using Cohen's $d$ using a pooled standard deviation. Effects are defined as follows: small $0.10 ;$ medium 0.5 ; large 0.8 ; very large 1.2 ; huge 2.0

\section{Participation and physical activity levels}

Table 2 shows the frequency of participation in parkrun. The full sample was registered for $3.13 \pm 2.53$ years; all sub-samples were registered more recently than the full sample with the deprived/inactive sub-sample registered for $2.28 \pm 1.80$ years $(p<0.001$; effect size $=0.34)$. The total number of parkruns run or walked was highly skewed with the full sample doing a mean of $46.0 \pm 61.1$ parkruns and median of 21 parkruns. The sub-samples completed fewer parkruns with the deprived/inactive sub-group doing least $(35.0 \pm 48.2$ parkruns; $p<0.05$; effect size $=0.18$ ). The mean number of parkruns per year run or walked by the full sample was $14.6 \pm 12.2$ and, although the deprived and inactive sub-samples were statistically different $(14.1 \pm 12.0$ and $15.5 \pm 12.5$ respectively), the effect sizes were small (0.04 and 0.08 respectively).

Comparison of the parkrun physical activity question asked at the survey compared to that asked at parkrun registration (see Additional file 2) showed that $88.2 \%$ of the inactive sub-sample reported an increase in their activity level following parkrun participation. A similar increase of $86.5 \%$ was found for the deprived/inactive subsample. The median number of days of activity for this previously inactive group had increased to 2 days of activity per week.

Table 2 shows findings from the single-item physical activity measure developed by Milton, Bull [24]. The full sample reported doing $3.59 \pm 1.77$ days of activity per week, while those in the inactive sub-sample reported $2.41 \pm 1.67$ days per week. Those in the deprived/inactive sub-sample reported a similar value of $2.47 \pm 1.71$ days of activity. The IPAQ-SF results (Table 2) indicated that $37.8 \%$ of the inactive sub-sample and $40.4 \%$ of the deprived/inactive sub-sample did physical activity that was vigorous enough to be health enhancing, according to the scoring system provided by IPAQ-SF [26].

\section{Perceived impact of running or walking at parkrun}

The reported benefits for the sub-samples are compared with the full sample in Table 3: response counts are shown in the table. All respondents tended to select no impact, better or much better for the 15 perceived impacts of parkrun. The proportion selecting worse or much worse was on average $0.5 \%$ for the 15 impacts, apart from 'the amount of time spent with family' at $6.2 \%$. 
Table 3 Perceived impact of running or walking at parkrun using the question "Thinking about the impact of parkrun on your health and wellbeing, to what extent has running or walking at parkrun changed:" Allowed responses were 'much worse, worse, no impact, better, much better'. Proportions are a combined value of 'better' and 'much better'

\begin{tabular}{|c|c|c|c|c|}
\hline Reporting 'better' or 'much better' & Full sample & Deprived sub-sample & Inactive sub-sample & Deprived / inactive sub-sample \\
\hline \multicolumn{5}{|l|}{ Your sense of personal achievement } \\
\hline $\mathrm{n}$ & 56,276 & 4131 & 2071 & 223 \\
\hline$\%$ & $90.7 \%$ & $91.7 \%$ & $93.4 \%$ & $93.3 \%$ \\
\hline \multicolumn{5}{|l|}{ Your fitness } \\
\hline $\mathrm{n}$ & 56,269 & 4125 & 2072 & 223 \\
\hline$\%$ & $89.3 \%$ & $91.3 \%$ & $92.9 \%$ & $92.4 \%$ \\
\hline \multicolumn{5}{|l|}{ Your physical health } \\
\hline $\mathrm{n}$ & 56,262 & 4134 & 2077 & 225 \\
\hline$\%$ & $84.7 \%$ & $87.0 \%$ & $88.5 \%$ & $89.8 \%$ \\
\hline \multicolumn{5}{|l|}{ Your happiness } \\
\hline $\mathrm{n}$ & 56,217 & 4126 & 2068 & 224 \\
\hline$\%$ & $78.8 \%$ & $81.8 \%$ & $80.8 \%$ & $83.5 \%$ \\
\hline \multicolumn{5}{|l|}{ The amount of time you spend outdoors } \\
\hline $\mathrm{n}$ & 56,251 & 4134 & 2076 & 225 \\
\hline$\%$ & $74.1 \%$ & $78.7 \%$ & $82.1 \%$ & $85.8 \%$ \\
\hline \multicolumn{5}{|l|}{ Your enjoyment of competing } \\
\hline $\mathrm{n}$ & 56,253 & 4126 & 2072 & 224 \\
\hline$\%$ & $72.7 \%$ & $74.2 \%$ & $70.6 \%$ & $70.1 \%$ \\
\hline \multicolumn{5}{|l|}{ How much you feel part of a community } \\
\hline $\mathrm{n}$ & 56,217 & 4120 & 2076 & 225 \\
\hline$\%$ & $69.7 \%$ & $70.6 \%$ & $68.2 \%$ & $69.8 \%$ \\
\hline \multicolumn{5}{|l|}{ Your mental health } \\
\hline $\mathrm{n}$ & 56,215 & 4127 & 2074 & 225 \\
\hline$\%$ & $69.3 \%$ & $73.9 \%$ & $72.3 \%$ & $76.4 \%$ \\
\hline \multicolumn{5}{|l|}{ Your confidence } \\
\hline $\mathrm{n}$ & 56,225 & 4132 & 2075 & 225 \\
\hline$\%$ & $61.3 \%$ & $66.3 \%$ & $64.0 \%$ & $70.7 \%$ \\
\hline \multicolumn{5}{|c|}{ Your ability to be active in a safe environment } \\
\hline $\mathrm{n}$ & 56,193 & 4122 & 2072 & 225 \\
\hline$\%$ & $59.9 \%$ & $65.3 \%$ & $69.3 \%$ & $72.4 \%$ \\
\hline \multicolumn{5}{|l|}{ The number of new people you meet } \\
\hline $\mathrm{n}$ & 56,237 & 4127 & 2075 & 225 \\
\hline$\%$ & $57.5 \%$ & $58.7 \%$ & $55.8 \%$ & $60.9 \%$ \\
\hline \multicolumn{5}{|l|}{ Your ability to control your weight } \\
\hline $\mathrm{n}$ & 56,208 & 4124 & 2074 & 224 \\
\hline$\%$ & $52.3 \%$ & $54.7 \%$ & $56.3 \%$ & $54.0 \%$ \\
\hline \multicolumn{5}{|c|}{ Your overall lifestyle choices (e.g. diet \& smoking) } \\
\hline $\mathrm{n}$ & 56,209 & 4118 & 2074 & 224 \\
\hline$\%$ & $51.8 \%$ & $56.4 \%$ & $57.2 \%$ & $65.2 \%$ \\
\hline \multicolumn{5}{|c|}{ The amount of time you spend with friends } \\
\hline $\mathrm{n}$ & 56,181 & 4125 & 2073 & 224 \\
\hline$\%$ & $41.1 \%$ & $42.4 \%$ & $41.1 \%$ & $46.0 \%$ \\
\hline
\end{tabular}


Table 3 Perceived impact of running or walking at parkrun using the question "Thinking about the impact of parkrun on your health and wellbeing, to what extent has running or walking at parkrun changed:" Allowed responses were 'much worse, worse, no impact, better, much better'. Proportions are a combined value of 'better' and 'much better' (Continued)

\begin{tabular}{|c|c|c|c|c|}
\hline Reporting 'better' or 'much better' & Full sample & Deprived sub-sample & Inactive sub-sample & Deprived / inactive sub-sample \\
\hline \multicolumn{5}{|c|}{ The amount of time you spend with family } \\
\hline$n$ & 56,140 & 4123 & 2071 & 224 \\
\hline$\%$ & $27.7 \%$ & $26.2 \%$ & $31.7 \%$ & $29.5 \%$ \\
\hline
\end{tabular}

Table 3 shows the proportions of respondents reporting only improvements to the measures since participating in parkrun, i.e. a combined value of those reporting 'better' and 'much better'. The data for the full sample shows that, 'sense of personal achievement' had the largest proportion of $90.7 \%$. The second highest rated measure was fitness $(89.3 \%)$ followed by physical health (84.7\%), happiness (78.8\%) and the amount of time spent outdoors (74.1\%). Mental health was improved for $69.3 \%$ of respondents and 'overall lifestyle choices' improved for $51.8 \%$.

The proportion reporting improvements on the perceived impacts tended to be higher for the deprived subsample, higher again for the inactive sub-sample and highest for the deprived/inactive sub-sample. A notable exception to this was 'enjoyment of competing' where the proportion decreased from $72.7 \%$ for the full sample to $70.6 \%$ for the inactive sub-sample and $70.1 \%$ for the deprived/inactive sub-sample.

\section{Discussion}

In this self-selected sample of parkrun participants, all respondents, irrespective of demographic characteristics and socioeconomic deprivations status, reported diverse benefits from participation in parkrun as runners/walkers. Whilst there was response bias in favour of those participating in parkrun more frequently, and fewer responses from those from more socioeconomically deprived areas and less active at registration, the scale of the survey ensured that comparison of these sub-groups with the sample as a whole was possible. We were able, for the first time, to compare benefits in those groups who have the greatest theoretical capacity to benefit from participation in parkrun with other sub-groups from within the parkrun population. This addresses a key priority linked to the achievement of population goals identified in the WHO's Global Action Plan on Physical Activity [1].

When compared to the full sample, the deprived, inactive and deprived/inactive sub-samples had a larger proportion of females, were younger, less likely to be retired and more likely to be unemployed; they were also more likely to be from a Black, Asian or other ethnic minority background and more likely to report having long-term health conditions. These factors could contribute to the lower happiness, life satisfaction and health score for the sub-samples, which warrants further investigation, especially as more of the deprived and inactive sub-groups reported improvements to health and wellbeing impacts due to parkrun compared to the full sample.

The parkrun participants (runners/walkers) in our survey who were previously inactive reported an increase in their activity levels from doing less than 1 day of activity per week at registration, to doing on average 2.4 days per week. Thus, in addition to the 15 or so parkruns completed per year on average, this would equate to another 111 days per year of physical activity outside parkrun; this increases to 115 days per year if they are also from more deprived areas. If the reported increases in physical activity observed here were to be replicated in the full parkrun population, then this could have substantial public health value. Given that individuals living in more socioeconomically deprived areas who are physically active may experience better health and quality of life than their neighbours who are less active [15], further research is needed to explore how community physical activity initiatives like parkrun can use strategies that promote inclusivity and encourage better representation from currently underrepresented populations.

Whilst the range and magnitude of benefits reported in this study indicate that respondents from across all sub-groups believe running or walking at parkrun impacted positively on their health and wellbeing, more of those who were from the most socioeconomically deprived areas, and those least active at registration, reported greater improvements than the full sample. Despite this, their self-reported health and wellbeing was consistently lower than the full sample, reflecting persistent and widely recognised health inequalities.

\section{Further research to explore factors related to benefits from participation}

There is a growing body of qualitative research exploring the motivations for participation in parkrun and the positive benefits experienced by those who attend [7-9, $29,30]$. Research has also explored the barriers to participation for specific communities and population groups and the potential for action research in 
developing inclusive strategies to increase participation by underrepresented groups [11]. Valuable insights could be gleaned from understanding the barriers to participation in community initiatives like parkrun among people from more inactive groups, including those from socioeconomically deprived areas. Such research would help build a more nuanced understanding of the factors that underpin participation. Working with communities to understand these challenges is an important step in designing inclusive strategies to promote participation that could potentially translate into important health benefits and contribute to reducing health inequalities.

Further analysis of matched parkrun data, using recorded parkrun participation as well as survey responses, could be used to explore the complex and bi-directional relationship between frequency of participation and changes in health and fitness (for which recorded parkrun completion times may be a proxy) and reported benefits. These relationships may vary for different types of benefit, with some benefits being experienced at lower levels of engagement and frequency of participation than others. It is also likely that overall perceived benefits may be related to the original motivation for participation.

The benefits related to volunteering at parkrun, as well as those related to running and walking should also be explored, as there is substantial evidence from previous research that there can be direct and substantial health and wellbeing benefits from volunteering, such as positive impacts on mental and physical health, life satisfaction, social well-being and depression [31]. The potential impact of parkrun volunteering, compared to running/walking at parkrun, is being explored by the authors separately. There is also potential for parkrun and similar community-based events to address current inequalities in both volunteering opportunities and the related benefits [32].

The overall benefits to a community are likely to be much greater than the sum of the benefits reported by individual participants. Wider benefits may include improved perceptions of the local area, increased economic activity if participants use local cafes and shops when attending an event [30], community spirit [29, 33] and linking stakeholders within a community, as seen in the UK's parkrun practice initiative [34]. Previous researchers have used a Social Return of Investment methodology to quantify the wider benefits due to sport [35]. A similar analysis of parkrun would allow potential funders, local authorities and those wishing to set up similar interventions to understand their social impact and return on investment.

\section{Implications for policy and practice}

The example of parkrun shows that large-scale, mass participation physical activity initiatives could impact positively on the health and wellbeing of participants and have the potential to address health inequalities. It has been assumed that the population groups with lowest levels of physical activity and highest risk of the associated chronic health conditions, who are also more likely to live in more socioeconomically deprived areas, potentially have the most to gain from being more active. However inequalities in personal and environmental resources, including access to transport and free time for recreation at weekends, and other social and cultural barriers to attendance, are reflected in disparities in health behaviours (e.g. recreational physical activity) [36]. In terms of motives, the results of this study imply that those from socioeconomically deprived areas, who were previously inactive, or both are more motivated by their health and improving their lifestyle than fitness, competition or training for other events. parkrun and other organisations might consider these factors when starting new community events.

This study shows that if these population groups do participate in recreational physical activity, they do (as might be hoped if not expected) report the highest levels of benefits. Further research is needed into the barriers experienced by people who theoretically have the most to gain from participation.

\section{Strengths and limitations}

The major strength of this study is the size and diversity of the dataset that ensured that, despite the low response rate and response bias expected for an email based online survey [20], the sample had the statistical power to explore variation between sub-groups of participants including those underrepresented in previous research i.e. those least active at registration and those living in the most socioeconomically deprived areas of the UK.

The findings should be interpreted in light of further methodological considerations. The cross-sectional nature of the data (a sub-sample of the parkrun population at one snapshot in time) means the associations observed cannot be inferred as causal; many influential factors outside of parkrun may have contributed to the positive changes observed. Longitudinal studies are needed to explore how parkrun and health and wellbeing interact over time.

The findings should be interpreted with small subsample sizes in mind, especially the deprived/inactive subsample. The socioeconomic deprivation status of respondents was not studied directly through questions about employment, income etc., but was inferred from IMD derived by the postcode provided at parkrun registration. This gave a proxy socioeconomic status measure for the area lived in when the respondent first registered with parkrun, rather than specific to the respondent at the time of survey completion. The survey was only available in online format in 
the English language which may potentially exclude people who had limited internet access or low literacy and digital literacy levels. Future implementation of this survey would benefit from designing, testing and piloting the survey with members of the public, especially those representing underrepresented groups such as people from Black, Asian and other ethnic minority backgrounds and those from areas of higher socioeconomic deprivation.

A further aspect of the survey design worthy of consideration is that a combination of pre-existing, validated survey questions and study-specific questions derived by the research team were used. This was deemed a pragmatic decision to ensure that responses were relevant to parkrun participation, but introduces some inconsistency to the methods and potential bias to the findings.

Response bias could also be assessed from the matching of survey responses to parkrun registration data available for the full sample. This indicates that the main difference between respondents and parkrun participants invited to complete the survey is in the number of parkrun events attended (14.5 vs. 3.7 parkruns per year). The results therefore relate to a sample that attend parkrun more often and that in addition may well have experienced higher levels of perceived benefit, leading in turn to both more frequent attendance and greater motivation to complete a questionnaire on their health and wellbeing in relation to parkrun participation.

Given this, we also undertook an analysis of a truncated sub-sample that was more representative of the parkrun participant population $(n=31,632)$ where the mean was 3.7 parkruns per year (achieved by excluding those who had done more than 8.85 parkruns per year; see Additional files 3 and 4). Even in this truncated sample, the benefits of parkrun to respondents were similar to the full sample.

\section{Conclusions}

Survey respondents, representing parkrun participants with a diverse range of demographic and socioeconomic characteristics and of physical activity levels at parkrun registration, reported a wide range of benefits that they credited to parkrun participation. Around 9 out of 10 of those who were previously inactive reported increases to their physical activity and similar proportions reported improvements to their physical health and fitness. This proportion increased further for those from socioeconomically deprived areas. The results show that parkrun and similar initiatives can introduce large numbers of people from diverse backgrounds to recreational physical activity and impact positively on a high proportion of them. It is important that future research helps identify how community initiatives like parkrun can better engage with those groups who potentially have most to gain from being more active in order to maximise impact.

\section{Abbreviations}

EQ-5D: EuroQol; EQ-VAS: EuroQol Visual Analogue Scale; IMD: Index of Multiple Deprivation; IPAQ-SF: International Physical Activity Questionnaire Short Form; LSOA: Lower Level Super Output Area; UK: United Kingdom; WHO: World Health Organization

\section{Supplementary Information}

The online version contains supplementary material available at https://doi. org/10.1186/s12889-021-11986-0.

Additional file 1 Survey details. Variables, outcome measures and questions captured in the parkrun Health and Wellbeing survey 2018.

Additional file 2. Activity change. Activity at the survey for those who were in the inactive category (less than once per week) at registration.

Additional file 3 Data from survey with truncated sample. Data for participants who were runners/walkers and runners/walkers who volunteer for the full sample and a truncated sample who participated in $\leq 8.85$ parkruns per year.

Additional file $\mathbf{4}$ Perceived impact with truncated sample. Perceived impact of running or walking at parkrun using the question "Thinking about the impact of parkrun on your health and wellbeing, to what extent has running or walking at parkrun changed". Allowed responses were 'much worse, worse, no impact, better, much better'. Data in the table is a combined value for 'better' and 'much better'. Results are compared to a truncated sample who participated in $\leq 8.85$ parkruns per year.

\section{Acknowledgements}

The authors would like to thank all the parkrun participants who completed the survey and to thank the parkrun Research Board for their support and guidance.

\section{Authors' contributions}

$\mathrm{CW}$ and $\mathrm{SH}$ conceived the idea of a parkrun health and wellbeing survey. $\mathrm{AB}$, $\mathrm{HQ}$ and SH designed the survey, sampling method and analysis plan; SH was responsible for the statistical analysis. $\mathrm{HQ}$, EG and $\mathrm{SH}$ drafted the manuscript. MG assisted with parkrun data acquisition and all authors contributed to the design of the survey and interpretation of the findings. RC, LR, and CS all contributed to design of the survey and interpretation of the data. All authors contributed to the writing of and approved the final manuscript.

\section{Funding}

Funding for this project was provided by parkrun. For the preparation of the manuscript, HQ is funded by a National Institute for Health Research (NIHR) School for Public Health Research (SPHR) post-doctoral launching fellowship. The NIHR SPHR played no role in the design of the study and collection, analysis, and interpretation of data and in writing the manuscript. Other authors have no funding to declare. The views, thoughts, and opinions expressed in the manuscript belong solely to the author/s, and do not necessarily reflect the position of parkrun, the parkrun Research Board or any funder(s).

\section{Availability of data and materials}

The datasets supporting the conclusions of this article are stored in the Sheffield Hallam University Research Database (SHURDA) for access and in accordance with the Data Protection Act 2018 and the General Data Protection Regulation 2018. In the hope of ensuring the full research potential of the dataset, a copy of the anonymised data will be accessible to researchers for research purposes through the parkrun Research Board, as originally outlined in the participant information sheet. Please contact Prof Steve Haake for details about requesting data: s.j.haake@shu.ac.uk.

\section{Declarations}

\section{Ethics approval and consent to participate}

The research design and consent procedures were reviewed and approved by Sheffield Hallam University Research Ethics Committee (Reference number: ER7034346). Written informed consent was received from all participants via the first page of the online survey. 


\section{Consent for publication}

Not applicable.

\section{Competing interests}

$A B, C W, C S, E G, H Q, L R, M G, R C, S H$ (author initials) are all parkrun registrants, but did not complete the survey. All authors were members of the parkrun Research Board (https://awrcparkrunresearch.wordpress.com/) based at the Advanced Wellbeing Research Centre (AWRC) at Sheffield Hallam University (UK) at the time of writing this paper. SH is the Chair of the parkrun Research Board. CW and MG are employees at parkrun. Parkrun commissioned Sheffield Hallam University (AB, HQ and SH) to conduct this survey. CW and MG (representing the funder) were involved in design of the study and matching data to the parkrun database, they approved the final manuscript. All other authors declare that they have no other competing interests.

\section{Author details}

${ }^{1}$ School of Health and Related Research, The University of Sheffield, 30 Regent St, Sheffield S1 4DA, UK. ${ }^{2}$ Advanced Wellbeing Research Centre, Sheffield Hallam University, Sheffield, UK. ${ }^{3}$ parkrun UK, Middlesex, UK. ${ }^{4}$ Prevention Research Collaboration, School of Public Health, University of Sydney, Sydney, New South Wales, Australia. ${ }^{5}$ School of Sport, Exercise and Health Sciences, Loughborough University, Loughborough, UK.

Received: 30 October 2020 Accepted: 12 October 2021

Published online: 02 November 2021

\section{References}

1. World Health Organization. Global Action Plan on Physical Activity 20182030: More Active People for a Healthier World: World Health Organization; 2018 [Available from: https://apps.who.int/iris/bitstream/handle/10665/272 722/9789241514187-eng.pdf.

2. Murphy N, Lane A, Bauman A. Leveraging mass participation events for sustainable health legacy. Leis Stud. 2015;34(6):758-66. https://doi.org/10.1 080/02614367.2015.1037787.

3. Bauman A, Murphy N, Lane A. The role of community programmes and mass events in promoting physical activity to patients. Br J Sports Med. 2009;43(1):44-6. https://doi.org/10.1136/bjsm.2008.054189.

4. Lane A, Murphy N, Bauman A. An effort to 'leverage'the effect of participation in a mass event on physical activity. Health Promot Int. 2013; 30(3):542-51. https://doi.org/10.1093/heapro/dat077.

5. Lane A, Murphy N, Smyth P, Bauman A. Do mass participation sporting events have a role in making populations more active? Research report 2. Ireland: Centre for Health Behaviour Research, Waterford Institute of Technology and Irish Sports Council; 2010.

6. Reece L, Quirk H, Wellington C, Haake SJ, Wilson F. Bright spots, physical activity investments that work: parkrun; a global initiative striving for healthier and happier communities. Br J Sports Med. 2019;53(6):326-7. https://doi.org/10.1136/bjsports-2018-100041.

7. Hindley D. "More than just a run in the park": an exploration of parkrun as a shared leisure space. Leis Sci. 2018;42(1):1-21. https://doi.org/10.1080/014 90400.2017.1410741.

8. Stevinson C, Wiltshire G, Hickson M. Facilitating participation in healthenhancing physical activity: a qualitative study of parkrun. Int J Behav Med. 2015;22(2):170-7. https://doi.org/10.1007/s12529-014-9431-5.

9. Morris $\mathrm{P}, \mathrm{Scott} \mathrm{H}$. Not just a run in the park: a qualitative exploration of parkrun and mental health. Adv Ment Health. 2018;17(2):1-14. https://doi. org/10.1080/18387357.2018.1509011.

10. Grunseit A, Richards J, Merom D. Running on a high: parkrun and personal well-being. BMC Public Health. 2018;18(1):59. https://doi.org/10.1186/s12889017-4620-1.

11. Fullagar S, Petris S, Sargent J, Allen S, Aktar M, Ozakinci G. Action research with parkrun UK volunteer organisers to develop inclusive strategies. Health Promot Int. 2019:daz113. https://doi.org/10.1093/heapro/daz113.

12. Schneider PP, Smith RA, Bullas AM, Quirk H, Bayley T, Haake SJ, Brennan A, Goyder E. Multiple deprivation and geographic distance to community physical activity events-Achieving equitable access to parkrun in England. Public health. 2020;189:48-53.

13. Smith RA, Schneider PP, Cosulich R, Quirk H, Bullas AM, Haake SJ, et al. Socioeconomic inequalities in distance to and participation in a community-based running and walking activity: a longitudinal ecological study of parkrun 2010 to 2019. Health Place. 2021;71:102626. https://doi org/10.1016/j.healthplace.2021.102626.

14. Smith R, Schneider P, Bullas A, Haake S, Quirk H, Cosulich R, et al. Does ethnic density influence community participation in mass participation physical activity events? The case of parkrun in England. Wellcome Open Res. 2020;5. https://doi.org/10.12688/wellcomeopenres.15657.1.

15. Johansson LM, Lingfors H, Golsäter M, Kristenson M, Fransson El. Can physical activity compensate for low socioeconomic status with regard to poor self-rated health and low quality-of-life? Health Qual Life Outcomes. 2019;17(1):33. https://doi.org/10.1186/s12955-019-1102-4.

16. Stevinson C, Hickson M. Changes in physical activity, weight and wellbeing outcomes among attendees of a weekly mass participation event: a prospective 12-month study. J Public Health. 2019;41(4):807-14. https://doi. org/10.1093/pubmed/fdy178.

17. Stevinson C, Hickson M. Exploring the public health potential of a mass community participation event. J Public Health. 2013;36(2):268-74. https:// doi.org/10.1093/pubmed/fdt082.

18. Bowness J, Tulle E, McKendrick J. Understanding the parkrun community; sacred Saturdays and organic solidarity of parkrunners. European Journal for Sport and Society. 2021;18(1):44-63.

19. Haake S, Quirk H, Bullas A. Parkrun Health and Wellbeing Survey 2018. https://awrcparkrunresearch.wordpress.com/2018/10/20/uk-ireland-parkrunhealth-wellbeing-survey-2018-\%e2\%9c\%93-output-available/: Advanced Wellbeing Research Centre, Sheffield Hallam University 2018.

20. Eysenbach $\mathrm{G}$. Improving the quality of web surveys: the checklist for reporting results of internet E-surveys (CHERRIES). J Med Internet Res. 2004; 6(3):e34. https://doi.org/10.2196/jmir.6.3.e34.

21. Office for National Statistics (ONS). Lower layer Super Output Area population estimates (supporting information): Office for National Statistics (ONS); 2017 [Available from: https://www.ons.gov.uk/peoplepopulationa ndcommunity/populationandmigration/populationestimates/datasets/ lowersuperoutputareamidyearpopulationestimates.

22. Office of National Statistics (ONS). Personal well-being in the UK: July 2017 to June 20182018 [Available from: https://www.ons.gov.uk/peoplepopula tionandcommunity/wellbeing/bulletins/measuringnationalwellbeing/july201 7tojune2018.

23. Brooks R, Group E. EuroQol: the current state of play. Health policy. 1996; 37(1):53-72. https://doi.org/10.1016/0168-8510(96)00822-6.

24. Cheng $L$, Tan RL-Y, Luo N. Measurement properties of the EQ VAS around the globe: a systematic review and Meta-regression analysis. Value Health. 2021;24(8):1223-33. https://doi.org/10.1016/j.jval.2021.02.003.

25. Milton K, Bull F, Bauman A. Reliability and validity testing of a single-item physical activity measure. Br J Sports Med. 2011;45(3):203-8. https://doi. org/10.1136/bjsm.2009.068395.

26. Craig CL, Marshall AL, Sjöström M, Bauman AE, Booth ML, Ainsworth BE, et al. International physical activity questionnaire: 12-country reliability and validity. Med Sci Sports Exerc. 2003;35(8):1381-95. https://doi.org/10.1249/01. MSS.0000078924.61453.FB.

27. Lee PH, Macfarlane DJ, Lam T, Stewart SM. Validity of the international physical activity questionnaire short form (IPAQ-SF): a systematic review. Int J Behav Nutr Phys Act. 2011;8(1):115. https://doi.org/10.1186/1479-5868-8-115.

28. Qualtrics. Qualtrics Software. Provo, Utah, USA 2019. Available at: https:// www.qualtrics.com.

29. Wiltshire G, Stevinson C. Exploring the role of social capital in communitybased physical activity: qualitative insights from parkrun. Qual Res Sport Exerc Health. 2018;10(1):47-62. https://doi.org/10.1080/2159676X.2017.13 76347.

30. Sharman MJ, Nash M, Cleland V. Health and broader community benefit of parkrun - an exploratory qualitative study. Health Promot J Australia. 2019; 30(2):163-71. https://doi.org/10.1002/hpja.182.

31. Yeung JW, Zhang Z, Kim TY. Volunteering and health benefits in general adults: cumulative effects and forms. BMC Public Health. 2018;18(1):1-8. https://doi.org/10.1186/s12889-017-4561-8.

32. Southby K, South J, Bagnall A-M. A rapid review of barriers to volunteering for potentially disadvantaged groups and implications for health inequalities. Volunt Int J Volunt Nonprofit Org. 2019;30(5):907-20. https:// doi.org/10.1007/s11266-019-00119-2.

33. Wiltshire G, Fullagar S, Stevinson C. Exploring parkrun as a social context for collective health practices: running with and against the moral imperatives of health responsibilisation. Sociol Health Illness. 2018;40(1):3-17. https://doi. org/10.1111/1467-9566.12622. 
34. Fleming J, Bryce C, Parsons J, Wellington C, Dale J. Engagement with and delivery of the 'parkrun practice initiative'in general practice: a mixed methods study. Br J Gen Pract. 2020;70(697):e573-80. https://doi.org/10.33 99/bjgp20X710453.

35. Davies LE, Taylor P, Ramchandani G, Christy E. Social return on investment (SROI) in sport: a model for measuring the value of participation in England. Int J Sport Policy Politics. 2019;11(4):585-605. https://doi.org/10.1080/194 06940.2019.1596967.

36. Pampel FC, Krueger PM, Denney JT. Socioeconomic disparities in health behaviors. Annu Rev Sociol. 2010;36(1):349-70. https://doi.org/10.1146/a nnurev.soc.012809.102529.

\section{Publisher's Note}

Springer Nature remains neutral with regard to jurisdictional claims in published maps and institutional affiliations.

Ready to submit your research? Choose BMC and benefit from:

- fast, convenient online submission

- thorough peer review by experienced researchers in your field

- rapid publication on acceptance

- support for research data, including large and complex data types

- gold Open Access which fosters wider collaboration and increased citations

- maximum visibility for your research: over $100 \mathrm{M}$ website views per year

At BMC, research is always in progress.

Learn more biomedcentral.com/submissions 